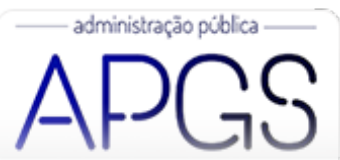

Administração Pública e Gestão Social ISSN: 2175-5787

apgs@ufv.br

Universidade Federal de Viçosa

Brasil

\title{
Planejamento Municipal em Debate: Trajetória e Prioridades no Município de Florianópolis
}

de Oliveira Menezes, Elaine Cristina; Chies Schommer, Paula; Carvalho Rocha, Arlindo; Pozzobon, Fernando

Planejamento Municipal em Debate: Trajetória e Prioridades no Município de Florianópolis

Administração Pública e Gestão Social, vol. 12, núm. 1, 2020

Universidade Federal de Viçosa, Brasil

Disponible en: http://www.redalyc.org/articulo.oa?id=351561601011

Esta obra está bajo una Licencia Creative Commons Atribución-NoComercial-SinDerivar 3.0 Internacional. 


\title{
Planejamento Municipal em Debate: Trajetória e Prioridades no Município de Florianópolis
}

\author{
Municipal Planning in Debate: the Trajectory and Priorities in The Municipality of Florianópolis \\ Planificación Municipal en Debate: Trajetoria y Prioridades en el Municipio de Florianópolis
}

Elaine Cristina de Oliveira Menezes

Redalyc: http://www.redalyc.org/articulo.oa?

Universidade Federal do Paraná, Brasil

$\mathrm{id}=351561601011$

eoliveira.menezes@gmail.com

Paula Chies Schommer

Universidade do Estado de Santa Catarina, Brasil

paulacs3@gmail.com

Arlindo Carvalho Rocha

Universidade do Estado de Santa Catarina, Brasil

arlindo.rocha@udesc.br

Fernando Pozzobon

Universidade do Estado de Santa Catarina, Brasil

fernando.esag@gmail.com

Recepción: 22 Marzo 2017

Aprobación: 18 Octubre 2018

Publicación: 01 Enero 2020

\section{Resumo:}

O trabalho analisa as prioridades do planejamento de investimento - planos trienais de investimentos e planos plurianuais - no município de Florianópolis de 1965 a 2017, apontando possíveis razões que as explicam. Partindo da trajetória do planejamento governamental brasileiro, examinam-se as prioridades na alocação de recursos nos sucessivos instrumentos de planejamento de investimento municipal. A pesquisa envolveu análise documental e entrevistas semiestruturadas, combinando abordagens quantitativa e qualitativa. Os resultados demonstram que de 1965 a 1988 priorizou-se infraestrutura e transporte, caracterizando uma agenda desenvolvimentista; de 1990 a 2017, a ênfase recaiu sobre saúde, educação e administração, alinhada às agendas gerencial e societal. Entre as razões estão as diretrizes da Constituição Federal de 1988, a centralidade do governo federal no delineamento de programas e projetos e o desenvolvimento de capacidade técnica e política local. Embora o município alcance bons indicadores socioeconômicos e aprendizagem social, há fragmentação da participação e desarticulação entre mecanismos de planejamento e alocação de recursos - setorial, entes federados, curto-longo prazo, governo-cidadania.

PalaVras-ChaVe: Planejamento para o desenvolvimento, Planejamento gerencial, Planejamento municipal.

\begin{abstract}
:
This paper analyzes the investment planning priorities - triennial investment plans and multiannual plans - in the Brazilian municipality of Florianópolis, from 1965 to 2017, pointing out reasons that explain these priorities. Based on the trajectory of Brazilian government planning, the article examines priorities in resource allocation, determined in the successive instruments of municipal investment planning. The results show that from 1965 to 1988 the municipal planning emphasized infrastructure and transportation and from 1990 to 2017, based on a managerial and social agenda, the emphasis was in areas like health, education and administration. Among the reasons there is the Federal Constitution of 1988 determinations, the centrality of the federal government in the design of programs and projects, and the development of local technical and political capacity. Although the city has achieved good relative results, in a social learning process, there are challenges such as the fragmentation of participation and the disarticulation between planning and resource allocation mechanisms (sectoral, federated entities, short-long term, governmentcitizenship).
\end{abstract}

KEYWORDS: Planning for development, Management planning, Municipal planning. 


\section{Resumen:}

Este trabajo analiza las prioridades de la planificación de inversiones - planes trienales de inversiones y planes plurianuales - en el municipio de Florianópolis, ubicado en el sur de Brasil, entre los años de 1965 y 2017, e identifica razones que las explican. A partir de la trayectoria de la planificación gubernamental brasileña, se examina las prioridades de recursos en los sucesivos instrumentos de planificación de inversiones municipales. La investigación involucró análisis documental y entrevistas semiestructuradas, combinando enfoques cuantitativos y cualitativos. Los resultados demuestran que, de 1965 hasta 1988 , se priorizó infraestructura y transporte, caracterizando una agenda desarrollista; de 1990 hasta 2017, el énfasis fue sobre la salud, la educación y la administración, alineada a las agendas gerencial y societal. Entre las razones están las directrices de la Constitución Federal Brasileña de 1988, la centralidad del gobierno federal en el delineamiento de programas y proyectos y las capacidades técnicas y política local. Aunque el municipio alcanza buenos indicadores socioeconómicos y aprendizaje social, hay fragmentación de la participación y desarticulación entre mecanismos de planificación y asignación de recursos (sectorial, entes federados, cortolargo plazo, gobierno-ciudadanía).

Palabras ClaVe: Planificación para el desarrollo, Planificación gerencial, Planificación municipal.

\section{INTRODUÇÃO}

A partir do final dos anos 1980, mecanismos gerenciais e participativos de planejamento ganharam espaço na agenda das reformas estatais brasileiras em lugar do planejamento para o desenvolvimento que havia se conformado no país a partir dos anos 1930 e predominado até o final dos anos 1970. Esses novos mecanismos estavam vinculados a expectativas democráticas de redução das desigualdades sociais e de melhoria do desempenho da administração pública (Bresser-Pereira, 1998; 2008; Paula, 2005; Pagnussat, 2006; Costa, 2008; Abrucio, 2008).

Nos últimos 30 anos, embora processos de gestão e relações de governo e governança tenham se transformado e a coordenação das políticas públicas tenha avançado (Souza, 2018; Souza \& Machado, 2018), o país ainda se mostra distante de alcançar patamares razoáveis em redução das desigualdades sociais, desempenho das instituições e equilíbrio econômico e socioambiental (Cardoso Jr., 2014; Menezes et al., 2015).

Um dos caminhos para responder aos desafios políticos, econômicos, sociais e ambientais do país seria a conformação de mecanismos de gestão que articulem o planejamento de forma ampla e orgânica. Para tanto, há que se conformar uma governança baseada na concertação entre diferentes atores sociais e governamentais, integrando o longo e o curto prazo, as diferentes políticas e serviços públicos, o nacional ao regional e local, e os governantes aos cidadãos (Menezes et al., 2015; Souza, 2018; Souza \& Machado, 2018).

É o que se espera verificar, em especial, nos municípios, considerando a relativa autonomia que ganharam a partir de 1988 e o potencial de proximidade entre governo e cidadania nessa escala. Entretanto, a articulação entre diferentes dimensões, horizontes temporais e instrumentos de planejamento e gestão constitui um grande desafio para os municípios. Um dos caminhos para compreender esse processo pode ser analisar quais são as prioridades de planejamento e alocação de recursos, as quais variam de um período para outro, por razões ainda pouco estudadas.

Antes da Constituição Federal de 1988 (CF/88), o que era priorizado no planejamento dos municípios? $\mathrm{O}$ que mudou ao longo dos anos nas suas prioridades, considerando seus instrumentos de planejamento e a alocação de recursos? Quais as possíveis razões para as mudanças? Como se verifica a vinculação entre as prioridades municipais e os dispositivos nacionais? Quais as possíveis condições que garantiriam maior grau de autonomia?

Para responder a essas indagações, este trabalho analisa as prioridades do planejamento de investimento (Planos Trienais de Investimentos - PTIs - e Planos Plurianuais - PPAs) no município de Florianópolis, de 1965 a 2017, e identifica as possíveis razões que explicam essas prioridades. Por meio dessa análise, fundamentada em perspectivas do planejamento - desenvolvimentista, gerencial e societal -, e em dados 
empíricos coletados entre 2015 e 2017, busca-se contribuir para o debate sobre planejamento municipal no Brasil.

O município de Florianópolis foi escolhido como foco da análise pois apresenta condições que contribuiriam para maior grau de autonomia na definição de prioridades de planejamento e alocação de recursos. A capital do estado de Santa Catarina é uma cidade de porte médio, que abriga o aparelho do estado e instituições de ensino superior. $\mathrm{O}$ município apresenta bons indicadores socioeconômicos, que o posicionam entre os melhores do país em rankings como os do Índice de Desenvolvimento Humano (IDH) e de Efetividade dos Municípios (IBGE, 2018; Atlas Brasil, 2018; REM-F, 2018). Isso contribui para atrair servidores públicos qualificados e o coloca acima da taxa média nacional em crescimento populacional (Sinais Vitais, 2018).

$\mathrm{Na}$ relação governo-cidadania, há iniciativas que se destacam positivamente, como a dos conselhos e das conferências de saúde, em meio a fragilidades e descontinuidades no uso de certos mecanismos, como orçamento participativo e plano diretor (Menezes et al., 2015). Entre as iniciativas recentes estão o projeto Floripa Te Quero Bem, de 2012, liderado por segmentos da sociedade civil e articulado em conjunto com uma rede na América Latina, que levou à aprovação do Plano de Metas (Dahmer, 2014), e a iniciativa Cidades Emergentes Sustentáveis (ICES), proposta pelo Banco Interamericano de Desenvolvimento (BID), e pela Caixa Econômica Federal (CEF), em cinco cidades médias brasileiras (FloripAmanhã, 2018).

Florianópolis, pelo que apresenta de similar a outros municípios, como os desafios de capacidade de financiamento e de coordenação federativa e fragmentação da participação (Paula 2005; Abrucio, 2008; Souza, 2018; Souza \& Machado, 2018), e pelo que se distingue deles, como a capacidade técnica dos servidores, permite supor que a análise das prioridades de seu planejamento ofereça pistas para compreender as características do planejamento municipal no Brasil.

$\mathrm{O}$ artigo é subdividido em cinco seções, incluindo esta introdução. A segunda seção apresenta uma revisão da literatura acerca do planejamento para o desenvolvimento gerencial e societal e das dinâmicas do planejamento municipal. A terceira é dedicada aos aspectos metodológicos. Na quarta, mostram-se os resultados da pesquisa, analisando o planejamento no município estudado, apontando suas prioridades e as razões que as explicam. Na última seção, são apresentadas as considerações finais, seguidas das referências.

\section{DO PLANEJAMENTO PARA O DESENVOLVIMENTO AO PLANEJAMENTO DE CUNHO GERENCIAL E SOCIETAL}

De acordo com Pagnussat (2006), não há uma teoria sobre planejamento, mas um campo de pensamento teórico-crítico sobre esse conceito, no qual as principais correntes de pensamento são: i) Análise de políticas, que aborda o planejamento "como uma forma de tomada de decisão antecipada, um processo cognitivo que utiliza a razão técnica para explorar e avaliar possíveis linhas de ação” (Pagnussat, 2006, p. 10); ii) aprendizagem social, que enfatiza os processos sociais na perspectiva dos agentes comprometidos com a prática; iii) reforma social, que compreende o planejamento como "[...] a aplicação do conhecimento científico aos assuntos públicos, preconizando a forte presença do Estado nesse processo, desempenhando papel condutivo e/ou mediador (Pagnussat, 2006, p. 12); iv) mobilização social, que formula uma crítica radical "às condições impostas pelo capitalismo industrial, às suas contradições, às suas injustiças e à exploração da classe trabalhadora pelo modo de produção capitalista” (Pagnussat, 2006, p. 13).

Tais correntes estão implicadas na forma de conceber e realizar o planejamento tanto em economias capitalistas como socialistas. Nas economias socialistas predomina o planejamento centralizado e os meios de produção são de propriedade ou coordenados pelo Estado. Nas economias capitalistas há predomínio da economia de mercado, sendo o planejamento menos centralizado no Estado e voltado à promoção do desenvolvimento (Pagnussat, 2006). A expansão do planejamento na esfera pública deu-se em ambas. 
Durante o século XX, alguns acontecimentos marcaram a história do planejamento público, entre eles: A revolução bolchevique (1917), que introduziu práticas de planejamento governamental centralizado e de médio prazo (planos quinquenais); a crise capitalista de 1929, que abriu espaço para o intervencionismo keynesiano (New Deal de Roosevelt, Plano Marshall e Comissariat au Plan); o pensamento latino-americano para superação do subdesenvolvimento, com esforços teóricos e práticos apoiados pela Comissão Econômica para a América Latina e o Caribe (Cepal), incluindo técnicas de programação de investimentos e difusão de ideias da industrialização; a crise do welfare state em países centrais, a partir da década de 1970, e a crise do nacional-desenvolvimentismo na América Latina, nas décadas de 1980 e 1990, que motivaram reformas do Estado e a introdução de um novo modelo de gerenciamento em diversos países, reformas essas, em países latino-americanos, acompanhadas de ajustes estruturais pautadas no Consenso de Washington (BresserPereira, 2008; Paula, 2005).

\section{Do PlanEJAMENTO PARA O DESENVOLVIMENTO AO PLANEJAMENTO GERENCIAL E SOCIETAL NO BRASIL}

O quadro histórico da gestão pública brasileira contempla diferentes abordagens e fatos relativos ao planejamento governamental. Para fins deste artigo, destacam-se duas perspectivas, a do planejamento ancorado no modelo desenvolvimentista, no período de 1950 a 1980, voltado para o longo prazo, com intervenção mais direta do Estado na economia, aproximando-se do pensamento da Cepal e do intervencionismo keynesiano pós crise de 1929 (Cardoso Jr., 2014; Cepal, 2000a; Cepal, 2000b; Pagnussat, 2006; Cardoso, 1993) e a que focaliza as inovações estabelecidas a partir da CF/88 (Brasil, 2015), que mescla o planejamento gerencial e os mecanismos de médio prazo, consubstanciados nos PPAs (Abrucio \& Loureiro, 2005; Giacomoni, 2012), articulando com dinâmicas de participação social, próprias da abordagem societal (Paula, 2005; Costa, 2008).

Outra forma de compreender distintos objetivos e mecanismos de planejamento governamental é a diferenciação entre Planos de Governo e Planos de Estado. As características que estariam no centro de cada tipo são sintetizadas no Quadro 1, a seguir:

Quadro 1: Diferenças entre planos de governo e planos de Estado

\begin{tabular}{|c|c|c|}
\hline Características & Plano de Governo & Plano de Estado \\
\hline Objetivo & $\begin{array}{l}\text { Realização de ações e } \\
\text { investimentos de médio } \\
\text { prazo. }\end{array}$ & $\begin{array}{l}\text { Realização de investimentos } \\
\text { setoriais e estratégicos de longo } \\
\text { prazo. }\end{array}$ \\
\hline Duração & $\begin{array}{l}4 \text { anos, com foco no } \\
\text { mandato. }\end{array}$ & $\begin{array}{l}\text { Acima de } 10 \text { anos, com foco no } \\
\text { longo prazo. }\end{array}$ \\
\hline Tipos de gastos & $\begin{array}{l}\text { De Capital e Correntes } \\
\text { decorrentes. }\end{array}$ & Fundamentalmente de Capital. \\
\hline Abrangência & $\begin{array}{l}\text { Alinhamento com as } \\
\text { diretrizes } \\
\text { econômico-financeiras. }\end{array}$ & $\begin{array}{l}\text { Diversas áreas setoriais e } \\
\text { integração das diferentes funções } \\
\text { de governo; Integração dos } \\
\text { diversos planos setoriaise } \\
\text { estratégicos. }\end{array}$ \\
\hline Tipos de Planos & Planos político-gerenciais. & Planos político-estratégicos. \\
\hline Temas relevantes & $\begin{array}{l}\text { Agendas de manutenção da } \\
\text { máquina pública e de } \\
\text { demandas sociais. }\end{array}$ & $\begin{array}{l}\text { Infraestrutura, sustentabilidade e } \\
\text { desenvolvimento socioeconômico. }\end{array}$ \\
\hline $\begin{array}{l}\text { Exemplos de } \\
\text { Planos }\end{array}$ & $\begin{array}{l}\text { PPA, Plano de Metas } \\
\text { (municipal) }\end{array}$ & $\begin{array}{l}\text { Planos setoriais; Planos de Metas } \\
\text { (JK); PND I; PND II; Planos de } \\
\text { estabilizaçăo econômica. }\end{array}$ \\
\hline
\end{tabular}

Fonte: Adaptado a partir de Cardoso Jr., 2014; Giambiagi \& Além, 2008; Cáceres, 2014. 
Durante a Primeira República há ausência de planejamento governamental no Brasil, com exceção do Convênio de Taubaté, em 1906, e a reação à crise de 1929, demonstrando o caráter reativo do Estado (Cardoso Jr., 2014). Após a década de 1930, o Estado brasileiro orienta-se à transformação das estruturas econômicas e sociais visando o desenvolvimento. As décadas de 1930 a 1970 foram permeadas por planejamentos de longo prazo, ilustrados pelos planos setoriais, plano de metas e planos nacionais de desenvolvimento, mais próximos de planos estatais ou planos político-estratégicos. Na década de 1980 tem-se a predominância de planos de curto prazo, voltados à estabilização monetária. Com base na $\mathrm{CF} / 88$, a década de 1990 trouxe um modelo de planejamento governamental de cunho operacional-legalista e de curto e médio prazo, caracterizado pelos PPAs, voltados a colocar em obra os planos de governo ou político-gerenciais.

A CF/88, além de definir novas funções e certa autonomia para estados e municípios, determina que os PPAs sejam alinhados aos planos e programas nacionais, regionais e setoriais (Brasil, 2015). Entretanto, as demandas de longo prazo, dentre elas as relativas a sustentabilidade e infraestrutura, ficam em segundo plano, bem como a integração das funções de governo para além do horizonte temporal de quatro anos.

Em cada ciclo político-econômico, segundo a análise de Cardoso Jr. (2014), certas dimensões do planejamento são priorizadas, conforme detalhado no Quadro 2.

\section{Quadro 2: Trajetória do planejamento no Brasil}

\begin{tabular}{|c|c|c|c|c|c|}
\hline $\begin{array}{l}\text { Ciclos político- } \\
\text { econômicos }\end{array}$ & $\begin{array}{l}\text { Padrão de } \\
\text { dominância do } \\
\text { Estado }\end{array}$ & $\begin{array}{l}\text { Contexto } \\
\text { econômico- } \\
\text { institucional }\end{array}$ & $\begin{array}{l}\text { Dimensões do } \\
\text { planejamento }\end{array}$ & $\begin{array}{l}\text { Contexto político- } \\
\text { institucional }\end{array}$ & $\begin{array}{l}\text { Dimensões da } \\
\text { gestão pública }\end{array}$ \\
\hline $\begin{array}{l}\text { 1889-1930 Primeira } \\
\text { República - } \\
\text { desenvolvimento para } \\
\text { fora }\end{array}$ & $\begin{array}{l}\text { Liberal- } \\
\text { oligárquica }\end{array}$ & $\begin{array}{l}\text { Economia } \\
\text { cafeeira - para } \\
\text { fora }\end{array}$ & $\begin{array}{l}\text { Ausência de } \\
\text { planejamento }\end{array}$ & $\begin{array}{l}\text { Montagem do } \\
\text { aparato estatal- } \\
\text { burocrático }\end{array}$ & Patrimonialista \\
\hline $\begin{array}{l}\text { 1933-1955: Era } \\
\text { Getúlio Vargas - } \\
\text { nacional- } \\
\text { desenvolvimentista }\end{array}$ & $\begin{array}{l}\text { Nacional- } \\
\text { populista }\end{array}$ & $\begin{array}{l}\text { Industrialização; } \\
\text { Substituição de } \\
\text { importações - } \\
\text { bens de consumo }\end{array}$ & $\begin{array}{l}\text { Planejamento } \\
\text { não sistêmico - } \\
\text { Planos setoriais }\end{array}$ & $\begin{array}{l}\text { Montagem do } \\
\text { Sistema } \\
\text { corporativo[i] }\end{array}$ & $\begin{array}{l}\text { Patrimonial- } \\
\text { burocrática DASP } \\
(1938)\end{array}$ \\
\hline $\begin{array}{l}\text { 1956-1964: Era JK - } \\
\text { internacionalização } \\
\text { econômica }\end{array}$ & $\begin{array}{l}\text { Estatal- } \\
\text { democrática }\end{array}$ & $\begin{array}{l}\text { Industrialização } \\
\text { pesada }\end{array}$ & $\begin{array}{l}\text { Planejamento } \\
\text { discricionário - } \\
\text { Plano Metas JK }\end{array}$ & $\begin{array}{l}\text { Acomodação e } \\
\text { crise do Modelo }\end{array}$ & $\begin{array}{l}\text { Patrimonial- } \\
\text { burocrática }\end{array}$ \\
\hline $\begin{array}{l}\text { 1964-1979: Regime } \\
\text { Militar }\end{array}$ & $\begin{array}{l}\text { Estatal- } \\
\text { autoritária }\end{array}$ & $\begin{array}{l}\text { Industrialização } \\
\text { II - milagre e } \\
\text { endividamento }\end{array}$ & $\begin{array}{l}\text { Planejamento } \\
\text { burocrático- } \\
\text { autocrático }\end{array}$ & $\begin{array}{l}\text { Consolidação } \\
\text { institucional- } \\
\text { autoritária }\end{array}$ & $\begin{array}{l}\text { Patrimonial- } \\
\text { burocrática - } \\
\text { PAEG }\end{array}$ \\
\hline $\begin{array}{l}\text { 1980-1989: } \\
\text { Redemocratização }\end{array}$ & $\begin{array}{l}\text { Liberal- } \\
\text { democrática }\end{array}$ & $\begin{array}{l}\text { Estagnação; } \\
\text { inflação; } \\
\text { endividamento }\end{array}$ & $\begin{array}{l}\text { Planos de } \\
\text { estabilização: } \\
\text { Cruzado, } \\
\text { Bresser, Verão }\end{array}$ & $\begin{array}{l}\text { Redemocratização } \\
\text { e reconstituição }\end{array}$ & $\begin{array}{l}\text { Patrimonial- } \\
\text { burocrática }\end{array}$ \\
\hline $\begin{array}{l}\text { 1990-2010: } \\
\text { Consolidação da } \\
\text { democracia - reformas } \\
\text { estruturais }\end{array}$ & $\begin{array}{l}\text { Liberal- } \\
\text { democrática }\end{array}$ & $\begin{array}{l}\text { Estagnação; } \\
\text { Inflação; } \\
\text { Endividamento }\end{array}$ & $\begin{array}{l}\text { Planos de } \\
\text { estabilização: } \\
\text { Collor, Real e } \\
\text { Plurianuais }\end{array}$ & $\begin{array}{l}\text { Consolidação } \\
\text { democrática, } \\
\text { reforma } \\
\text { gerencialista e } \\
\text { experimentalismo } \\
\text { societal }\end{array}$ & $\begin{array}{l}\text { Patrimonial- } \\
\text { burocrática, } \\
\text { gerencialista e } \\
\text { societal }\end{array}$ \\
\hline
\end{tabular}

Fonte: Extraído de Cardoso Jr (2014, p. 30).

Observa-se que os planos setoriais e de metas (Plano Salte, Plano de Metas de Juscelino Kubitschek e Plano Trienal de Celso Furtado) buscam o horizonte temporal do longo prazo. Já os programas de trabalho dos PPAs (1991-1995; 1996-1999; 2000-2003; 2008-2011; 2012-2015) são de médio prazo.

O processo de transformação social e econômica produzido entre 1950 e 1980 revelou-se frágil nas décadas seguintes, com o endividamento externo, estagnação e inflação persistentes. A redemocratização, a partir da década de 1980, foi limitada pelos severos constrangimentos da política de controle do endividamento e da 
inflação. O planejamento governamental voltou-se para planos de estabilização econômica de curto prazo, iniciando o desmantelamento da função planejamento (Cardoso Jr., 2014).

Durante a década de 1990, verifica-se o esgotamento e desmonte da função e das instituições de planejamento governamental, do modo como haviam sido delineadas a partir de 1930. Ganha força o discurso de caráter liberal, tanto econômico como político (Cardoso Jr., 2014), alinhado com as recomendações do Consenso de Washington para os países latino-americanos e a agenda de reforma gerencial do Estado, em paralelo com a agenda democrática (Bresser-Pereira, 2008; Paula, 2005).

Ao analisar o contexto da gestão pública brasileira nos anos 1990, Paula (2005) identifica dois projetos políticos em disputa, ambos afirmando que buscavam contribuir para ampliar a democracia no país, o primeiro inspirado na vertente gerencial da gestão pública, que se constituiu no Brasil durante os anos 1990, no governo do presidente Fernando Henrique Cardoso; o segundo tem como principal referencial a vertente societal, que se manifesta nas experiências participativas de gestão pública, sobretudo no âmbito municipal, como os conselhos gestores de políticas públicas e o orçamento participativo, e possui suas raízes no ideário das mobilizações populares contra a ditadura militar e pela democratização do país, baseado nos movimentos sociais iniciados na década de 1960.

A origem da vertente gerencial está no debate sobre a crise de governabilidade e a credibilidade do Estado na América Latina durante as décadas de 1980 e 1990. Tal debate se insere no contexto internacional de reforma do aparelho do Estado, iniciado na Europa e nos Estados Unidos (Bresser-Pereira, 1998; Paula, 2005). A reforma proposta em 1995 no Brasil foi denominada por Bresser Pereira (2008) como modelo estrutural de gerência pública, e teve como referência principal a experiência britânica. $\mathrm{O}$ modelo surge em contraponto à crise do nacional-desenvolvimentismo e às críticas ao patrimonialismo e ao autoritarismo do Estado brasileiro (Bresser-Pereira, 1998; Paula, 2005).

Desta forma, o planejamento gerencial, por meio dos PPAs, apresentado pela CF/88, foi reforçado pela perspectiva implantada na década de 1990 (Abrucio \& Loureiro, 2005; Bresser-Pereira, 1998). Paula (2005) observa, contudo, que ao longo dos anos 1990, as iniciativas de aliar o projeto político à ampliação da participação se desenvolveram de forma fragmentada. $\mathrm{Na}$ vertente gerencial, a ênfase recaiu sobre as dimensões econômico-financeira e institucional-administrativa. Já as iniciativas de vertente societal enfatizaram a participação social e procuravam estruturar um projeto político para repensar o modelo de desenvolvimento brasileiro frente à crise nacional-desenvolvimentista, à estrutura do aparelho do Estado e ao paradigma de gestão (Paula, 2005). Ambas as vertentes, gerencial e societal, influenciaram a dinâmica do planejamento governamental brasileiro a partir dos anos 1990. A fragmentação de que fala Paula (2005) será visível nos municípios, como detalhado adiante.

Abrucio e Loureiro (2005) observam que a função planejamento foi convertida, a partir dos anos 1990, em PPAs sob dois princípios: A proposta de processo contínuo e pouco disruptivo, integrando o primeiro ano de mandato ao último ano planejado pelo governante antecessor e a compatibilização entre plano e orçamento (recursos financeiros), Lei Orçamentária Anual (LOA) e sua execução/gestão propriamente dita (metas físicas) - com a Lei de Diretrizes Orçamentárias (LDO) -, responsável por definir as metas (fiscais) e prioridades para o exercício seguinte (Brasil, 2015). Para Cardoso Jr. (2014), como vimos, essa concepção de planejamento, priorizando o cunho operacional e a agenda gerencial e de reforma do Estado, acarretou o esvaziamento da função planejamento como vital à formulação de diretrizes estratégicas (de médio e longo prazo) de desenvolvimento para o país.

No âmbito setorial, em áreas como saúde, educação e planejamento urbano, houve fortalecimento do planejamento e da gestão nas últimas três décadas. Dentre as razões para tal, estão os movimentos sociais dos anos 1970, como os movimentos populares dos pobres urbanos em nível local e o movimento sanitarista por um Sistema Único de Saúde (Avritzer, 2012), que influenciaram a CF/88. A Constituição estabeleceu mínimos de aplicação de recursos para as áreas de saúde e educação, concedeu mais autonomia aos municípios na execução das políticas e serviços, introduziu novos mecanismos de planejamento urbano, bem como 
mecanismos institucionais de participação cidadã na deliberação e no controle social, como conselhos, conferências e audiências públicas (Brasil, 2015).

Houve também iniciativas de aproximação entre Estado, mercado e sociedade civil no desenho e na provisão de serviços. Saúde e educação tornaram-se prioritárias para o desenvolvimento da nação, dados os recursos investidos, o desenvolvimento de capacidade técnica estatal e de sistemas de planejamento e gestão. Esses planejamentos contemplam, em certo grau, o horizonte de médio prazo e a articulação entre níveis de governo e destes com a sociedade civil e o mercado.

Cabe mencionar, ainda, iniciativas de planejamento para o desenvolvimento regional e para a sustentabilidade, ocorridas no Brasil em fins da década de 1990 e início dos anos 2000. Na dimensão socioeconômica do desenvolvimento, refletindo tendência verificada em países europeus, tem-se iniciativas voltadas à dinamização de sistemas produtivos locais (SPLs), denominados no Brasil de Arranjos Produtivos Locais (APLs) (Lastres \& Cassiolato, 2003; Lemos, 2003; Menezes, 2009). Na dimensão socioambiental, na esteira do debate internacional do ecodesenvolvimento dos anos 1960 e do desenvolvimento sustentável dos anos 1980, o Brasil passa a incorporar instrumentos de planejamento e gestão ambiental, como a Agenda 21 (Sachs, 1993; 2007; Vieira, 2006; Vieira \& Weber, 2000).

Como outras iniciativas, tem-se os fóruns de desenvolvimento local, os comitês de bacias hidrográficas e os consórcios públicos, que permitiram diversos arranjos de cooperação intermunicipal para planejar de forma integrada a região (Casarotto \& Pires, 2001; Frank \& Vibrans, 2003). A partir de 2007, há a tentativa de retomada de algumas ações de planejamento de caráter desenvolvimentista, aproximando setor público e setor privado, no Plano de Aceleração do Crescimento (PAC) (Brasil, 2017). Algumas dessas iniciativas persistem até hoje, como os consórcios públicos e os comitês de bacias, enquanto outras perderam vigor.

Em síntese, retomando os tipos de planos mencionados no Quadro 1, pode-se dizer que o planejamento político-gerencial ganhou destaque no país a partir da década de 1990, incluindo elementos sociais e democráticos, ainda que fosse limitado em termos de implementação e resultados. Já o planejamento políticoestratégico perdeu força como diretriz do planejamento brasileiro, ainda que tenha sido contemplado em algumas iniciativas. Em alguns setores como saúde e educação, houve ênfase a planejamento e gestão, com certo grau de articulação entre o curto e médio prazo, e entre níveis de governo e destes com a sociedade civil e o mercado.

\section{Planejamento municipal}

O planejamento de investimento municipal anterior à implementação da CF/88 era o denominado Orçamento Plurianual de Investimento (OPI), definido na Lei 4.320/1964, mantido pela Constituição de 1967 (Artigo 63) e regulamentado pela Lei Complementar no 3, de 7 de dezembro de 1967, que estipulava a elaboração de estimativas de investimentos para um prazo mínimo de três anos (Garcia, 2015).

Com mais autonomia a partir da $\mathrm{CF} / 88$, ainda que limitada pela centralização de recursos e pelas exigências para acesso aos mesmos, os municípios passaram a utilizar um conjunto de instrumentos de planejamento, muitos deles prevendo participação cidadã na deliberação e monitoramento da execução, por meio de conferências, conselhos e audiências públicas. Estão sintetizados na Figura 1, a seguir, os Planos Setoriais, como é o caso da saúde e da educação, de médio prazo, articulados com as diretrizes dos seus respectivos ministérios, portanto, vinculados aos objetivos e propostas do governo central, além dos planos de governo locais; os Planos de Ordenamento Territorial, ou Plano Diretor, de horizonte de médio e longo prazo; os Planos de Desenvolvimento que, quando existem, costumam ser de longo prazo e podem ser protagonizados pelo governo ou por segmentos da sociedade civil local; os Programas de governo, conjunto de propostas e ações discutidos durante o processo eleitoral, representando as expectativas e objetivos da sociedade local em cada momento político. Esse conjunto de instrumentos deve articular-se aos instrumentos de Planejamento e execução orçamentária, traduzidos nas leis PPA, LDO e LOA. 
Figura 1: Sistema de planejamento municipal brasileiro e sua relação com participação

\begin{tabular}{|c|c|c|}
\hline \multicolumn{3}{|c|}{ Instrumentos de planejamento setorial, ordenamento territorial e de governo } \\
\hline $\begin{array}{l}\text { Instrumentos de } \\
\text { Planejamento }\end{array}$ & $\begin{array}{l}\text { Horizonte } \\
\text { temporal }\end{array}$ & $\begin{array}{l}\text { Características de articulação entre } \\
\text { planejamento e participação }\end{array}$ \\
\hline $\begin{array}{l}\text { Planos Setoriais } \\
\text { Planos Municipais ou } \\
\text { Regionais de Saúde, } \\
\text { Educação, } \\
\text { Saneamento, } \\
\text { Habitação, etc. }\end{array}$ & $\begin{array}{l}\text { Em torno de } 10 \\
\text { anos }\end{array}$ & $\begin{array}{l}\text { Exigidos e articulados com politicas setoriais } \\
\text { nacionais; Elaborados pelo Executivo, com } \\
\text { base em Conferências Municipais; Monitorados } \\
\text { pelos Conselhos Municipais de Politicas } \\
\text { Públicas. }\end{array}$ \\
\hline $\begin{array}{l}\text { Ordenamento } \\
\text { Territorial Plano } \\
\text { Diretor }\end{array}$ & Mais de 10 anos & $\begin{array}{l}\text { Exigido pela Constituição, Estatuto da Cidade e } \\
\text { outras leis federais; Proposto pelo Executivo, } \\
\text { aprovado e controlado pelo Legislativo e pelo } \\
\text { Conselho da Cidade e Conferências da Cidade; } \\
\text { Há audiências públicas na elaboração. }\end{array}$ \\
\hline $\begin{array}{l}\text { Planos de } \\
\text { desenvolvimento }\end{array}$ & Mais de 10 anos & $\begin{array}{l}\text { Reúne aspirações de longo prazo de diferentes } \\
\text { segmentos da sociedade, baseadas em um } \\
\text { conjunto de indicadores e projeçōes. }\end{array}$ \\
\hline $\begin{array}{l}\text { Programas de } \\
\text { Governo Propostas } \\
\text { do gestor público } \\
\text { durante processo } \\
\text { eleitoral }\end{array}$ & $4 \operatorname{anos}$ & $\begin{array}{l}\text { Subsidia o debate eleitoral e as decisões dos } \\
\text { eleitores; Idealmente baliza o PPA e demais } \\
\text { planos; Propicia o controle das promessas } \\
\text { eleitorais. }\end{array}$ \\
\hline
\end{tabular}

\begin{tabular}{|c|c|c|}
\hline \multicolumn{3}{|c|}{ Instrumentos de planejamento e gestão dos recursos públicos } \\
\hline $\begin{array}{l}\text { Instrumentos de } \\
\text { planejamento e } \\
\text { execução } \\
\text { orçamentária }\end{array}$ & $\begin{array}{l}\text { Horizonte } \\
\text { temporal }\end{array}$ & $\begin{array}{l}\text { Características de articulação entre } \\
\text { planejamento e participação }\end{array}$ \\
\hline $\begin{array}{l}\text { Plano Plurianual, } \\
\text { PPA }\end{array}$ & $\begin{array}{l}4 \text { anos } \\
\text { Elaborado no } 1^{\circ} \\
\text { ano de } \\
\text { mandato, } \\
\text { executado entre } \\
\text { o } 2^{\circ} \text { ano e } 1^{\circ} \\
\text { ano do mandato } \\
\text { seguinte }\end{array}$ & \multirow{3}{*}{$\begin{array}{l}\text { O PPA é a lei proposta pelo Executivo, aprovada } \\
\text { e controlada pelo Legislativo, com auxílio do } \\
\text { Tribunal de Contas, e pelos Conselhos de } \\
\text { Políticas Públicas; Contempla promessas } \\
\text { eleitorais, articula o curto ao médio prazo } \\
\text { (previsão); Audiências públicas na elaboração e } \\
\text { prestação de contas (previsão legal); Dados da } \\
\text { execução portais de transparência; Prevê } \\
\text { punição pela Lei de Responsabilidade Fiscal, } \\
\text { que limita despesas com pessoal e } \\
\text { endividamento público; O orçamento é } \\
\text { autorizativo, sem garantia de que será } \\
\text { executado. }\end{array}$} \\
\hline $\begin{array}{l}\text { Lei de Diretrizes } \\
\text { Orçamentária, LDO }\end{array}$ & Anual & \\
\hline $\begin{array}{l}\text { Lei de Orçamento } \\
\text { Anual, LOA }\end{array}$ & Anual & \\
\hline
\end{tabular}




\begin{tabular}{lll}
$\begin{array}{l}\text { Outros instrumentos à disposição } \\
\text { Instrumentos }\end{array}$ & $\begin{array}{l}\text { Horizonte } \\
\text { temporal }\end{array}$ & $\begin{array}{l}\text { Características de articulação entre } \\
\text { planejamento e participação }\end{array}$ \\
$\begin{array}{l}\text { Orçamento } \\
\text { participativo }\end{array}$ & Anual & $\begin{array}{l}\text { População participa da deliberação sobre parte } \\
\text { dos investimentos contemplados na LOA }\end{array}$ \\
$\begin{array}{l}\text { Planos integrados } \\
\text { setoriais } \\
\text { metropolitanos }\end{array}$ & $\begin{array}{l}\text { Em torno de } 10 \\
\text { anos }\end{array}$ & $\begin{array}{l}\text { Articulados a políticas setoriais nacionais, } \\
\text { como mobilidade e saneamento }\end{array}$ \\
$\begin{array}{l}\text { Plano de metas } \\
4 \text { anos }\end{array}$ & $\begin{array}{l}\text { Instrumento proposto pela sociedade civil; } \text { O } \\
\text { prefeito apresenta metas e indicadores e presta } \\
\text { contas durante o mandato para o Legislativo e } \\
\text { a sociedade civil }\end{array}$ \\
$\begin{array}{l}\text { Projetos para } \\
\text { captação de } \\
\text { recursos }\end{array}$ & $\begin{array}{l}\text { A depender do } \\
\text { projeto e do } \\
\text { financiador }\end{array}$ & $\begin{array}{l}\text { Emal, envolve consulta à população em } \\
\text { certas etapas }\end{array}$ \\
\hline
\end{tabular}

Fonte: elaborado pelos autores.

Cada governo pode utilizar, ainda, instrumentos adicionais, a depender de sua estratégia de gestão e de busca de recursos, como orçamento participativo, planos integrados setoriais por região metropolitana, em áreas como mobilidade e saneamento, além de planos exigidos por financiadores de projetos, como os vinculados a programas do governo federal ou agentes externos, como o BID. Os governos são também influenciados pelas diretrizes estabelecidas nos Objetivos de Desenvolvimento do Milênio - ODM - e nos Objetivos do Desenvolvimento Sustentável - ODS (ONU, 2018).

Em algumas cidades, há, ainda, iniciativas de segmentos da sociedade civil, como a do Plano de Metas, adotado em cidades da América Latina, como Córdoba, , São Paulo e Florianópolis (Cáceres, 2014; Dahmer, 2014), exigindo dos prefeitos municipais a elaboração de diagnósticos e planos, com metas e indicadores que permitam a prestação de contas e o monitoramento mais direto pelo Legislativo e pela sociedade civil, durante os mandatos.

Com base nesses referenciais, analisa-se, a seguir, as prioridades do planejamento de investimentos (PTIs e PPAs) no município de Florianópolis, de 1965 a 2017, buscando identificar possíveis razões que as explicam. Observa-se, ainda, como se dá a articulação entre tais planos e outros instrumentos de planejamento e articulação entre governo e sociedade nesse período.

\section{ASPECTOS METODOLÓGICOS}

Este é um estudo empírico, de caráter exploratório-descritivo (Triviños, 1987) e abordagem quantitativaqualitativa. O município de Florianópolis foi escolhido como foco da análise pois apresenta condições que contribuiriam para certo grau de autonomia na definição de prioridades de planejamento e alocação de recursos, ao mesmo tempo em que é influenciado por características gerais do planejamento e da alocação de recursos do Brasil. Entre essas características, que afetam a autonomia dos municípios brasileiros, estão os desafios de capacidade de financiamento, coordenação federativa e articulação entre os instrumentos de planejamento, além da fragmentação da participação cidadã (Paula 2005; Abrucio, 2008; Souza, 2018; Souza \& Machado, 2018).

Florianópolis, com população estimada de 485 mil habitantes (IBGE, 2018), apresenta o $3^{\circ}$ maior Índice de Desenvolvimento Humano Municipal (IDHM) entre os municípios do país (0,847 em 2010), e PIB per capita em 2015 de R $\$ 39.678,10$ (IBGE, 2018; Atlas Brasil, 2018). Isso contribui para a atração de servidores públicos qualificados e para o crescimento populacional. A população de Florianópolis cresceu, entre 2000 e 
2010, a uma taxa média anual de 2,09\%, enquanto a do Brasil cresceu, em média, 1,17\% ao ano (Sinais Vitais, 2018). É a segunda capital no Ranking de Eficiência dos Municípios em 2016, enquanto Santa Catarina é o estado mais eficiente segundo o Ranking de Eficiência dos Estados em 2018 (REE-F, 2018; REM-F, 2018).

$\mathrm{Na}$ relação governo-cidadania, ao longo do tempo, o município apresenta fragilidades e descontinuidade no uso de mecanismos de participação, como orçamento participativo, conselhos de políticas públicas e plano diretor (Menezes et al., 2015). Ao mesmo tempo, há conselhos e conferências que se destacam, como na saúde, bem como engajamento da sociedade em iniciativas diversas. Entre elas, o Floripa Te Quero Bem (FTQB), de 2012, ligado à Rede Latino-Americana por Cidades e Territórios Justos, Democráticos e Sustentáveis (RCTJDS), instituindo o Plano de Metas (Dahmer, 2014; Cáceres, 2014; Hernandez \& Cuadros, 2014; Menezes, 2015) e a Iniciativa Cidades Emergentes Sustentáveis (ICES), proposta e coordenada pelo Banco Interamericano de Desenvolvimento (BID), e pela CEF, em cinco cidades médias brasileiras, a qual levou à constituição da Rede de Monitoramento Cidadão, em 2017 (FloripAmanhã, 2018).

O interesse pelas prioridades de planejamento e alocação de recursos no município ocorreu no âmbito de pesquisa anterior sobre participação cidadã, governança e accountability em cidades latino-americanas, na qual se focalizou a iniciativa Floripa Te Quero Bem e os setores saúde e segurança pública, que apresentam características distintas em termos de estrutura de planejamento e gestão, atribuições do município e participação cidadã. No curso da pesquisa sobre o período recente, revelou-se necessário conhecer mais sobre a trajetória de planejamento nas décadas anteriores, definindo-se o ano de 1965 como ponto de partida por ser o primeiro a ter dados sistematizados.

Os dados históricos foram obtidos nos documentos disponíveis junto à Secretaria de Planejamento Municipal e ao Arquivo Histórico de Florianópolis. Além disso, foram realizadas seis entrevistas semiestruturadas com: Três gestores do Executivo municipal, das secretarias de Planejamento, Saúde e Segurança Pública; um representante do Poder Legislativo, membro da Comissão de Orçamento e Finanças e dois integrantes de conselhos de políticas públicas, um da saúde, outro da segurança. As entrevistas foram realizadas entre 2015 e 2016, indagando sobre as características dos processos e instrumentos de planejamento utilizados na cidade, as prioridades estabelecidas nos planos e as razóes para tal, bem como desafios e perspectivas do planejamento na cidade. 
Quadro 3: Matriz teórico-metodológica

\begin{tabular}{|c|c|c|c|c|}
\hline Dimensões & Conceitos & Coleta de dados & $\begin{array}{l}\text { Análise dos } \\
\text { dados }\end{array}$ & Quadro teórico \\
\hline Descritiva & $\begin{array}{l}\text { Planos de } \\
\text { governo e } \\
\text { instrumentos de } \\
\text { orçamentação; } \\
\text { Trajetória do } \\
\text { planejamento } \\
\text { municipal. }\end{array}$ & $\begin{array}{l}\text { Registros do } \\
\text { arquivo histórico } \\
\text { municipal; Dados } \\
\text { dos PPAS; Portal } \\
\text { da transparência. }\end{array}$ & $\begin{array}{l}\text { Análise } \\
\text { descritiva }\end{array}$ & $\begin{array}{l}\text { Giambiagi e } \\
\text { Além (2007); } \\
\text { Giacomoni } \\
\text { (2012); Brasil } \\
\text { (2015). }\end{array}$ \\
\hline Explicativa & $\begin{array}{l}\text { Planejamento } \\
\text { para o } \\
\text { desenvolvimento; } \\
\text { Planejamento } \\
\text { gerencial; Razões } \\
\text { das prioridades } \\
\text { do planejamento. }\end{array}$ & $\begin{array}{l}\text { Entrevistas } \\
\text { semiestruturadas } \\
\text { com } \\
\text { representantes } \\
\text { das secretarias } \\
\text { municipais de } \\
\text { planejamento, } \\
\text { saúde e } \\
\text { segurança } \\
\text { pública, do } \\
\text { Legislativo e dos } \\
\text { conselhos de } \\
\text { políticas públicas } \\
\text { da saúde e } \\
\text { segurança. } \\
\text { pública. }\end{array}$ & $\begin{array}{l}\text { Análise de } \\
\text { conteúdo }\end{array}$ & $\begin{array}{l}\text { Giacomoni } \\
\text { (2012); Cardoso } \\
\text { Jr (2014); Cepal } \\
\text { (2000a); Cepal } \\
\text { (2000b); Abrucio } \\
\text { e Loureiro } \\
\text { (2005); Abrucio } \\
\text { (2008); Costa } \\
\text { (2008); } \\
\text { Bresser-Pereira } \\
\text { (1998; 2008); } \\
\text { Paula (2005). }\end{array}$ \\
\hline Prospectiva & $\begin{array}{l}\text { Razões e } \\
\text { inovações no } \\
\text { planejamento } \\
\text { governamental } \\
\text { (abordagens } \\
\text { gerencial e } \\
\text { societal) }\end{array}$ & $\begin{array}{l}\text { Entrevistas } \\
\text { semiestruturada } \\
\text { com } \\
\text { representantes } \\
\text { das secretarias } \\
\text { municipais de } \\
\text { planejamento, } \\
\text { saúdee } \\
\text { segurança } \\
\text { pública, do Poder } \\
\text { Legislativo e dos } \\
\text { conselhos de } \\
\text { políticas públicas } \\
\text { da saúde e } \\
\text { segurança } \\
\text { pública }\end{array}$ & $\begin{array}{l}\text { Análise de } \\
\text { conteúdo }\end{array}$ & $\begin{array}{l}\text { Cáceres (2014); } \\
\text { Paula (2005). }\end{array}$ \\
\hline
\end{tabular}

A interpretação dos dados se deu de acordo com as técnicas de análise descritiva dos dados quantitativos e análise de conteúdo dos dados das entrevistas (Triviños, 1987; Richardson, 1985), relacionando-as com o referencial teórico assumido, conforme descrito no Quadro 3. A análise deu-se em três fases: i) análise descritiva dos achados históricos do período de 1965 a 2017, com dados quantitativos obtidos junto ao Arquivo Histórico Municipal entre 2014 e 2015, sendo que os documentos foram PTIs e PPAs; ii) análise explicativa dos achados históricos e das entrevistas à luz do referencial teórico mobilizado constante no Quadro 3, por meio da técnica da análise de conteúdo; e iii) análise prospectiva, identificando possíveis razões das prioridades e inovações do planejamento em Florianópolis, seus limites e potencialidades. 


\section{ANÁLISE DO PLANEJAMENTO MUNICIPAL DE FLORIANÓPOLIS}

O planejamento nos municípios brasileiros ocorre por meio de um conjunto de instrumentos, conforme destacado no item 2.2 e na Figura 1. Neste trabalho, focaliza-se a análise dos PTIs e do Plano de Desenvolvimento Econômico Municipal (Pladem) no município de Florianópolis, no período anterior à $\mathrm{CF} / 1988$. No pós 1988 , focalizam-se as leis orçamentárias, particularmente o PPA, e iniciativas da sociedade civil que influenciaram o planejamento.

Verifica-se que, no período de 1965 a 1981, o planejamento em Florianópolis esteve alinhado com os Planos Nacionais de Desenvolvimento. O Pladem de 1965 convergia com a lógica do planejamento desenvolvimentista de inspiração cepalina, na qual havia um apelo à melhoria de infraestrutura para a industrialização do país (Cepal, 2000a; 2000b; Cardoso Jr, 2014). Os recursos do Pladem para o exercício de 1965 e 1966 foram assim distribuídos: (a) 5\% para investimentos em educação supletiva; (b) 5\% para a área de saúde pública; (c) $20 \%$ destinados à instituição de fundo relativo à pavimentação de ruas elogradouros; (d) 40\% para obras rodoviárias, execução de grades e calçamentos e (e) $30 \%$ para serviços ligados ao abastecimento e distribuição de gêneros alimentícios. Verifica-se que o Pladem priorizava a execução e o aperfeiçoamento de obras e serviços para o desenvolvimento econômico e social do município. Tais investimentos eram considerados basilares para o desenvolvimento de longo prazo, ainda que o período de vigência do plano possa ser considerado de médio prazo.

Os dados do Pladem e dos PTIs em Florianópolis, de 1969 a 1981, demonstram os maiores percentuais de investimentos nas funções de governo habitação e urbanismo e transportes, conforme Tabela 1, a seguir:

Tabela 1: Dados percentuais do investimento planejado do município de Florianópolis - 1965 a 1981

\begin{tabular}{|c|c|c|c|c|c|c|c|c|c|c|}
\hline Período & $65-66$ & $69-71$ & $73-75$ & $74-76$ & $75-77$ & $76-78$ & $77-79$ & $78-80$ & $79-81$ & Média \\
\hline Administração & 0,000 & 22,124 & 10,050 & 10,125 & 15,770 & 17,184 & 14,507 & 7,476 & 9,023 & 11,807 \\
\hline Agricultura & 30,000 & 0,137 & 2,837 & 2,438 & 0,513 & 1,630 & 0,975 & 1,575 & 0,415 & 4,502 \\
\hline $\begin{array}{l}\text { Assistência e } \\
\text { previdência }\end{array}$ & 0,000 & 0,519 & 0,617 & 0,672 & 0,000 & 1,189 & 0,530 & 0,375 & 3,521 & 0,825 \\
\hline $\begin{array}{l}\text { Educaçãoe } \\
\text { cultura. }\end{array}$ & 5,000 & 9,682 & 14,204 & 15,720 & 9,581 & 10,154 & 15,826 & 5,452 & 10,509 & 10,681 \\
\hline $\begin{array}{l}\text { Habitação e } \\
\text { urbanismo }\end{array}$ & 60,000 & 55,918 & 38,920 & 36,164 & 43,898 & 46,714 & 6,405 & 9,849 & 11,577 & 34,383 \\
\hline $\begin{array}{l}\text { Indústria, } \\
\text { comércio e } \\
\text { serviços }\end{array}$ & 0,000 & 1,861 & 11,765 & 12,435 & 7,388 & 3,299 & 2,110 & 1,740 & 1,073 & 4,630 \\
\hline $\begin{array}{l}\text { Saúde e } \\
\text { saneamento }\end{array}$ & 5,000 & 9,759 & 3,941 & 4,399 & 10,488 & 3,081 & 10,923 & 30,903 & 20,619 & 11,012 \\
\hline Transportes & 0,000 & 0,000 & 17,666 & 18,046 & 11,367 & 15,916 & 48,269 & 42,322 & 43,199 & 21,865 \\
\hline $\begin{array}{l}\text { Reserva de } \\
\text { contingência }\end{array}$ & 0,000 & 0,000 & 0,000 & 0,000 & 0,000 & 0,000 & 0,000 & 0,000 & 0,000 & 0,000 \\
\hline Outros & 0,000 & 0,000 & 0,000 & 0,000 & 0,995 & 0,833 & 0,456 & 0,308 & 0,064 & 0,295 \\
\hline
\end{tabular}

Os dados da Tabela 1 demonstram que habitação e urbanismo, na década de 1960, apresentavam percentuais de investimento superiores a 50\% dos recursos. Já a função transportes ganha prioridade no final dos anos 1970, com aproximadamente 40\% dos recursos investidos. As décadas de 1960 e 1970 foram, portanto, marcadas por investimentos em infraestrutura de habitação e urbanismo e em transporte, em conformidade com o Programa de Ação Econômica do Governo (PAEG) no âmbito federal (Cardoso Jr., 
2014). Essa tendência deu-se em função das diretrizes do governo federal para transformar o Brasil, um país agrário-exportador, em industrial. Isso demandou estrutura urbana para receber a população que migraria do campo para a cidade, bem como infraestrutura de transporte para distribuição da produção industrial (portos, aeroportos, estradas, etc.). No estado de Santa Catarina, este período foi marcado pelos Planos de Metas do Governo Estadual (Plameg) I e II, sendo este último ligado às áreas de energia, transporte e industrialização (Goularti Filho, 2002). Já as funções saúde e educação oscilam nesse período, crescendo no final dos anos 1970 no município, com média de $11 \%$ dos recursos investidos.

No período de 1980 a 1988, os investimentos planejados por Florianópolis foram direcionados para as áreas de transportes, com aproximadamente $55 \%$ do orçamento de investimentos e, para a administração, com aproximadamente $20 \%$. É o que mostra a tabela 2, a seguir:

Tabela 2: Dados percentuais do investimento planejado do município de Florianópolis - 1980 a 1990

$\begin{array}{lllllllll}\text { Período } & \mathbf{8 0 - 8 2} & \mathbf{8 1 - 8 3} & \mathbf{8 2 - 8 4} & \mathbf{8 3 - 8 5} & \mathbf{8 4 - 8 6} & \mathbf{8 5 - 8 7} & \mathbf{8 6 - 8 8} & \text { Média } \\ \text { Administração } & \mathbf{7 , 3 8 0} & 10,707 & 15,237 & 19,371 & \mathbf{1 6 , 8 2 5} & \mathbf{3 7 , 1 2 4} & \mathbf{3 3 , 0 2 7} & \mathbf{1 9 , 9 5 3} \\ \text { Agricultura } & 0,000 & 0,000 & 0,000 & 0,000 & 0,000 & 0,000 & 0,005 & \mathbf{0 , 0 0 1} \\ \text { Assistência e previdência } & 1,150 & 3,141 & 1,347 & 2,044 & 6,314 & 3,243 & 1,711 & \mathbf{2 , 7 0 7} \\ \text { Educação e Cultura } & 3,187 & 4,770 & 11,130 & 3,594 & 8,682 & 7,968 & 4,606 & \mathbf{6 , 2 7 6} \\ \text { Habitação e urbanismo } & 17,405 & 7,231 & 3,071 & 0,478 & 0,873 & 0,028 & 0,296 & \mathbf{4 , 1 9 7} \\ \text { Indústria, Comércioe } & & & & & & & & \\ \text { Serviço } & 0,208 & 1,879 & 2,856 & 0,247 & 0,014 & 0,141 & 0,182 & \mathbf{0 , 7 9 0} \\ \text { Saúde e saneamento } & 16,089 & 17,047 & 7,497 & 4,987 & 8,310 & 4,303 & 1,655 & \mathbf{8 , 5 5 5} \\ \text { Transportes } & 54,388 & 54,632 & 58,263 & 65,914 & 53,928 & 41,808 & 56,025 & \mathbf{5 4 , 9 9 4} \\ \text { Reserva de contingência } & 0,000 & 0,000 & 0,000 & 0,000 & 5,0242 & 4,636 & 2,172 & \mathbf{1 , 6 9 0} \\ \text { Outros } & 0,194 & 0,593 & 0,599 & 3,366 & 5,053 & 5,386 & 2,494 & \mathbf{2 , 5 2 6}\end{array}$

Fonte: Produzido pelos autores a partir de dados documentais obtidos no arquivo histórico de Florianópolis. * Os dados são apresentados em termos percentuais em função das diferentes moedas que existiram no Brasil nos períodos pesquisados.

Ocorre, portanto, nesse período, redução significativa dos investimentos em habitação e urbanismo e aumento progressivo na área de administração. Esse direcionamento reflete a crise de endividamento do país, com a União priorizando os planos de estabilização - Cruzado, Bresser e Verão (Cardoso Jr., 2014).

A transição entre os PTIs e os PPAs apresenta-se pouco clara nas leis municipais de Florianópolis. Os PPAs de 1990 a 2000 mostram apenas objetivos e ações. Em alguns poucos, constam os projetos e locais dos investimentos. Entretanto, tais planos não indicam dotações orçamentárias e valores a serem investidos entre 1990 a 2000 (Parecer ao PL 5.834/93).

Já a Tabela 3, a seguir, apresenta os investimentos priorizados no período 2002-2017: 


\begin{tabular}{|c|c|c|c|c|c|}
\hline Período & $2002-2005$ & $2006-2009$ & $2010-2013$ & $2014-2017$ & Média \\
\hline Administração & 23,972 & 28,992 & 13,753 & 23,068 & 22,446 \\
\hline Agricultura & 0,263 & 0,004 & 0,000 & 0,000 & 0,067 \\
\hline $\begin{array}{l}\text { Assistência e } \\
\text { previdência }\end{array}$ & 2,373 & 7,437 & 8,943 & 8,073 & 6,706 \\
\hline $\begin{array}{l}\text { Educação e } \\
\text { Cultura }\end{array}$ & 20,554 & 23,543 & 18,101 & 20,433 & 20,658 \\
\hline $\begin{array}{l}\text { Habitação e } \\
\text { urbanismo }\end{array}$ & 6,145 & 8,516 & 19,055 & 16,793 & 12,627 \\
\hline $\begin{array}{l}\text { Indústria, } \\
\text { Comércio e } \\
\text { Serviço }\end{array}$ & 1,400 & 0,265 & 1,259 & 0,682 & 0,901 \\
\hline $\begin{array}{l}\text { Saúde e } \\
\text { saneamento }\end{array}$ & 26,258 & 21,942 & 26,661 & 17,560 & 23,105 \\
\hline Transportes & 7,813 & 0,358 & 0,696 & 2,185 & 2,763 \\
\hline $\begin{array}{l}\text { Reserva de } \\
\text { contingência }\end{array}$ & 0,2126 & 0,9517 & 0,3662 & 0,2397 & 0,443 \\
\hline Outros & 11,222 & 8,944 & 11,533 & 11,206 & 10,726 \\
\hline
\end{tabular}

Fonte: Produzido pelos autores a partir de dados documentais obtidos no arquivo histórico de Florianópolis. * Os dados são apresentados em termos percentuais em função das diferentes moedas que existiram no Brasil nos períodos pesquisados.

Os dados indicam que as prioridades do município se invertem quando comparadas ao período entre 1965 e 1980. A partir de 2002, os maiores investimentos ocorrem em saúde e saneamento, com aproximadamente $23 \%$ do orçamento de investimento, seguidos por administração, com $22 \%$ dos recursos, e educação, com cerca de $20 \%$.

Em síntese, a Figura 2, a seguir, ilustra as principais funções de governo no período de 1965 a 2017.

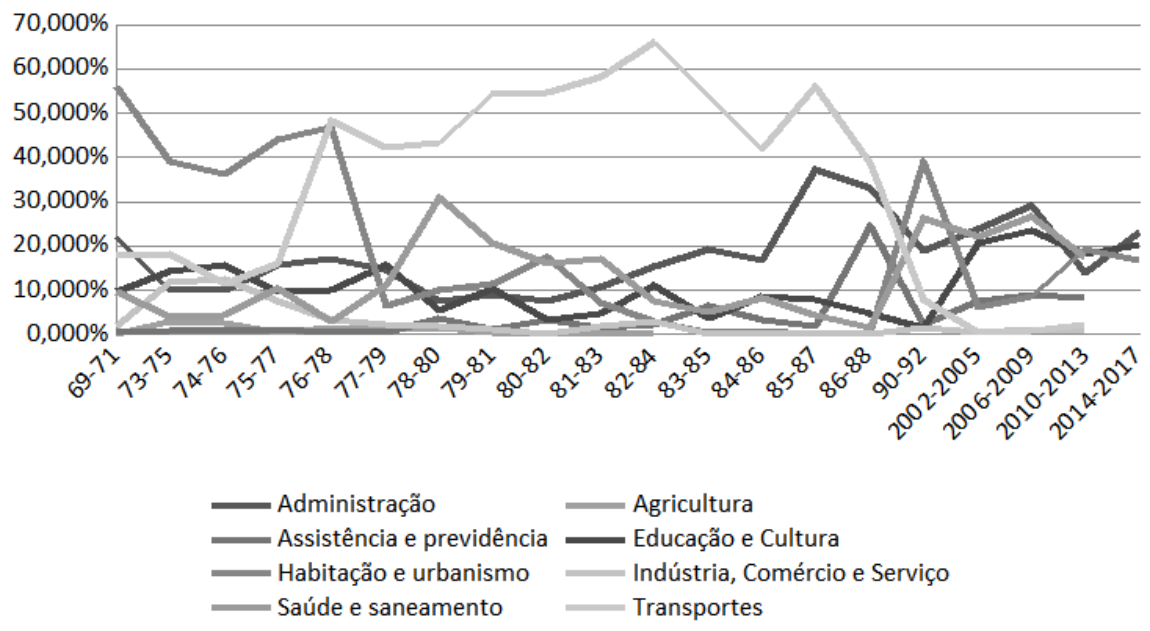

Figura 2: Tendências das prioridades inseridas nos planos do município de Florianópolis Fonte: Produzido pelos autores a partir de dados documentais obtidos no arquivo histórico de Florianópolis.

Infere-se que as prioridades no planejamento de Florianópolis estiveram alinhadas com as do planejamento nacional.

$\mathrm{Na}$ transição política entre o regime militar e o democrático, tendo como marco a $\mathrm{CF} / 88$, ocorrem a estruturação dos sistemas de garantia de direitos e mudanças no pacto federativo, incluindo novas atribuições e funções aos entes federados, além da alteração na concepção e nas prioridades do planejamento. 
Nessa concepção, dá-se a passagem dos PTIs para os PPAs, os quais exigem programas de trabalho indicando objetivos, metas e indicadores de resultado, o que nem sempre ganha adesão efetiva nos municípios. Nas prioridades, altera-se a ênfase da infraestrutura para saúde e educação, que passam a ser consideradas as bases para o desenvolvimento de longo prazo, e nas quais estados e municípios adquirem papel mais ativo.

$\mathrm{Na}$ economia, busca-se a estabilização. As grandes obras de infraestrutura, antes financiadas pelo governo militar centralizado, após 1988, passam a ser negociadas por meio dos espaços federativos institucionais do Executivo e do Legislativo, ainda sob a regulação e coordenação da esfera federal, por meio de transferências voluntárias. Outra estratégia do pós-1988 para obras de infraestrutura são as privatizações, concessões, permissões e parcerias público-privadas.

Em Florianópolis, o setor de transportes, por exemplo, prioridade até a década de 1980, com mais de 50\% dos recursos, passa a contar, nos anos 2000 , com pouco menos de $3 \%$ dos investimentos previstos para o período, o que demonstra tal inversão das prioridades.

A queda dos investimentos na área de transporte é acompanhada pelo crescimento nas áreas de administração, saúde e saneamento e educação e cultura, enquanto os investimentos nas outras áreas permanecem constantes, como é o caso da indústria, do comércio e serviço e da agricultura.

A pesquisa demonstrou, ainda, que os limites mínimos de investimentos definidos na $\mathrm{CF} / 88,15 \%$ da receita corrente líquida na saúde e $25 \%$ na educação, norteiam a alocação de recursos no âmbito municipal. Porém, as crescentes expectativas sobre essas áreas fazem com que os recursos sejam vistos como insuficientes, ainda que muito superiores ao que se investia no passado. Um dos entrevistados observa que as expectativas da população em relação aos investimentos públicos em saúde e educação cresceram nos últimos anos, assim como cresceu a infraestrutura de unidades e equipes de saúde e educação no município. Essas duas secretarias, juntas, concentram mais de $50 \%$ dos servidores. Entretanto, na saúde, com o crescimento dos custos com novos tratamentos, aumento da população na cidade e aumento da expectativa de vida, tem-se como tendência a demanda crescente por recursos, deixando outras áreas desatendidas.

O entrevistado observa, ainda, que eventualmente há recursos federais para construção de novas unidades, porém, o custeio dessas unidades exige o aporte de recursos adicionais pelos municípios, recursos esses que não estão disponíveis, quer seja por limites de arrecadação, quer pelos tetos definidos pela LRF.

O custo do material [sic], uma policlínica para ser mantida é $\mathrm{R} \$ 1.500 .000,00$ por ano. É até fácil de construir, o governo federal até ajuda a construir, mas depois é a manutenção. A educação são 30\%, nós temos uma educação de qualidade, e a população exige cada vez mais [...]. Então, saúde e educação são mais de 50\%, e os demais? As demais secretarias? É bastante difícil [...] o crescimento da nossa cidade, a cada dia que passa estão vindo muitas pessoas para nossa cidade (Representante do Poder Legislativo Municipal).

Diante do quadro descrito até aqui, é possível identificar algumas razões para a inversão verificada ao longo do tempo nos investimentos e alocação de recursos. Destacam-se inicialmente as de caráter mais geral, que afetam o conjunto dos municípios:

- A determinação da CF/88 de percentuais mínimos de aplicação de recursos por parte dos municípios, particularmente em saúde e educação (Brasil, 2015);

- A influência da lógica sistêmica e coordenada de políticas setoriais nacionais, como saúde, educação e assistência social (Souza, 2018), que obriga os municípios a investirem de determinada maneira para receberem recursos federais, incluindo fundos específicos;

- A predominância de dinâmicas de investimento setoriais conformadas em programas ministeriais, acessíveis aos municípios por meio de projetos específicos;

- O PPA consubstanciando-se em um modelo de planejamento que se aproxima dos Planos de Governo, com ênfase no médio prazo, priorizando as demandas mais prementes da sociedade, em lugar do planejamento com ênfase estratégica e de longo prazo (Planos de Estado) (Cardoso Jr, 2014; Giambiagi \& Além, 2008; Cáceres, 2014). 
Para Giambiagi e Além (2009), o modelo de descentralização adotado no Brasil a partir da CF/88 pode ser visto como um misto entre o modelo de eleição pública local, em que as decisões partem do cidadão no processo eleitoral, e o modelo do principal-agente, em que existe uma espécie de contrato entre o governo central e os entes subnacionais que recebem transferências.

O entrevistado da Secretaria de Planejamento de Florianópolis enfatiza a relevância do processo eleitoral na definição das prioridades do governante, se eleito:

O plano de governo de um prefeito, pelo próprio planejamento brasileiro, ele se dá no transcorrer do processo eleitoral [...]. Então, aquilo tudo que durante a campanha ele debateu exaustivamente, [...] construiu junto com a população, ele vai colocar isso dentro de uma legalidade, ou seja, num instrumento de planejamento chamado de Plano Plurianual, porque assim a Constituição determina (Representante da Secretaria de Planejamento Municipal).

Essa vinculação entre programa de governo e o PPA é limitada pelo modelo principal-agente (Giambiagi \& Além, 2009). Os municípios têm, afinal, pouca autonomia para decidir a sua alocação de acordo com as expectativas dos cidadãos (Abrucio \& Loureiro, 2005) e responder a mudanças do ambiente, tais como as demográficas.

Parte dos recursos da União é entregue a estados e municípios por meio de transferências tributárias constitucionais. Outra parte é descentralizada por intermédio de transferências voluntárias, as quais limitam a aplicação desses recursos a programas definidos pela União e aumentam o peso da barganha política nas negociações (Souza, 2018; Souza \& Machado, 2018). Quando os municípios buscam financiar-se, na maioria das vezes, dependem de aval e garantia da União. De acordo com Soares e Machado (2018, p. 26), "a ause\#ncia de recursos financeiros pro\#prios cria uma situac\#a\#o de depende\#ncia dos entes em relac\#a\#o a\#queles que controlam esses recursos, geralmente o centro".

Em síntese, embora a CF/88 tenha fortalecido o federalismo brasileiro (fiscal e administrativamente), aumentando a autonomia fiscal de estados e municípios e atribuindo-lhes novas competências e recursos, a influência da União ainda é grande, tanto na definição de diretrizes e normas, como na alocação dos recursos e coordenação das políticas públicas (Giambiagi \& Além, 2009; Souza, 2018; Abrucio \& Loureiro, 2005; Souza \& Machado, 2018). Por outro lado, embora haja limites do federalismo brasileiro, a institucionalizac\#a\#o de mecanismos de coordenação e de arenas intergovernamentais para implementac\#a\#o das poli\#ticas sociais, com representac\#o\#es das tre\#s esferas de governos, constitui-se como inovac\#a\#o no processo de descentralização (Souza \& Machado, 2018), algo que varia de uma política para outra, em grau de complexidade e resultados.

Tal tensão gerada pela descentralização de recursos brasileira, que combina os modelos da eleição pública local e do principal-agente, é visível em Florianópolis, por exemplo, nas áreas de saúde e segurança.

Os instrumentos de planejamento e gestão em saúde buscam conciliar as diretrizes, programas e recursos nacionais com as especificidades, prioridades e recursos locais, incorporando a visão de profissionais, usuários e prestadores de serviços, por meio de conferências regionais e municipais e dos conselhos locais e municipal de saúde.

Já na segurança pública, dado o desenho institucional, o papel do município é residual. Todavia, o tema preocupa os cidadãos. É apontado como prioritário por iniciativas sociais como o FTQB, o ICES e os Conselhos Comunitários de Segurança (Consegs), que pressionam o governo local. Sem recursos e políticas claras por parte do município, suas respostas têm sido pontuais, a exemplo da criação da Guarda Municipal e da Secretaria Municipal de Segurança Pública, ainda frágeis institucionalmente (FloripAmanhã, 2018; Sinais Vitais, 2018).

Embora esse tipo de tensão se verifique em todos os municípios, devido à similaridade normativa e à distribuição de recursos entre os entes federados, há diferenças nos seus efeitos, em função de diversidades regionais e de características socioeconômicas, políticas, demográficas e técnicas em cada local.

Embora os municípios sejam relativamente autônomos para aderir às políticas e aos programas federais (Giambiagi \& Além, 2009), não é fácil implementar a gestão local e criar programas, pois muitos desses não 
possuem quadro técnico capacitado para elaborar projetos e concorrer aos editais ministeriais. Não é o caso de Florianópolis, que conta com quadros qualificados, sobretudo em educação e saúde.

Esse é um dos fatores particulares que influenciam o desempenho do município, junto a outros identificados na pesquisa, a exemplo de:

- Capacidade técnica e qualificação contínua dos servidores, aliada à capacidade de negociação política, facilitando melhorias na gestão e acesso a recursos por meio de projetos;

- Papel do município como capital de estado e sede de região metropolitana, coordenando redes regionais e participando da definição de políticas;

- Continuidade de um mesmo secretário e equipe de gestão da pasta sob mandatos de diferentes partidos, priorizando no município pesquisado, no caso da saúde, a Estratégia da Saúde da Família (ênfase na atenção primária), por exemplo;

- Dinâmica de conselhos municipais e locais de políticas públicas, a exemplo da saúde;

- Engajamento da sociedade civil por meio de iniciativas de planejamento, gestão e monitoramento.

A pesquisa demonstrou que são grandes os desafios de articulação entre os instrumentos de planejamento na cidade, como o PPA, os planos setoriais, o Plano Diretor e os programas de cada governante. Diante das fragilidades dos planos existentes, associada à dificuldade da sociedade civil em acompanhar a definição de prioridades e sua execução, segmentos da sociedade civil reuniram-se, em 2012, no movimento FTQB, buscando articular mecanismos de participação, planejamento e responsabilização (Dahmer, 2014; Cáceres, 2014). Além de levantar indicadores e desafios da cidade e discuti-los com especialistas, governos e candidatos, propuseram o Plano de Metas, que prevê que os futuros prefeitos apresentem, no início do mandato, um diagnóstico detalhado, metas, responsáveis e indicadores, prestando contas das mesmas ao longo dos quatro anos.

Aprovado pelo Legislativo em 2013 como emenda à Lei Orgânica do Município, o Plano de Metas foi elaborado pelo prefeito para o período 2013-2016. Embora tenha havido eventos de prestação de contas ao longo do mandato, ele foi pouco articulado aos instrumentos existentes, como o PPA e os planos setoriais. Seu uso foi descontinuado ao final do período.

O processo teve continuidade, em parte, quando Florianópolis passou a integrar o programa ICES, liderado pelo BID e pela CEF, em 2013. Foi realizado um diagnóstico detalhado, apontadas perspectivas para o desenvolvimento da cidade e preparados projetos para futura captação de recursos. Em 2017, formou-se a Rede de Monitoramento Cidadão (RMC), que acompanha indicadores da cidade, envolvendo organizações da sociedade civil (OSCs), universidades, mídia e segmentos empresariais (FloripAmanhã, 2018).

Essas iniciativas demonstram articulação entre as abordagens gerencial e societal (Bresser-Pereira, 2008; Paula, 2005), estimulando a adoção de metas e indicadores nas diversas áreas e sua divulgação regular para monitoramento pelo Legislativo e pela sociedade e promovendo aprendizagem social através da ampliação de possibilidades de envolvimento de cidadãos, OSCs e governantes no debate sobre os desafios da cidade. Isso pode qualificar ações e o debate eleitoral ao apresentar dados e indicadores que evidenciam desafios e avanços, além de simplificar a linguagem do planejamento, definir prazos e responsáveis pela sua execução e facilitar o controle social (Menezes et al., 2015; Cáceres, 2014). É também oportunidade para que diferentes secretarias se reúnam e conheçam a atuação das demais, algo que ocorreu no período de 2013 a 2016 e não era comum na cidade.

Entretanto, há contínuos desafios de articulação entre os vários segmentos da sociedade e desses com o Executivo e o Legislativo municipal e os conselhos de políticas públicas. O FTQB, por exemplo, embora tenha engajado diversos segmentos na discussão das prioridades e do primeiro plano, desarticulou-se pouco depois de aprovada a Lei e elaborado o primeiro Plano de Metas. Alguns de seus membros se envolveram no ICES e RMC, outros não. De parte da gestão pública local, por sua vez, observou-se dificuldade de incorporação de uma lógica gerencial e participativa, mais articulada e transparente em relação ao planejamento. 
Menezes et al. (2015), ao avaliar o conteúdo e o processo do Plano de Metas 2013-2016, observam: i) Ausência de ligação entre o curto e o longo prazo; ii) pouca menção à integração entre ações no âmbito municipal, estadual e federal em resposta aos desafios apontados e pouca autonomia na aplicação dos recursos; iii) pouca integração entre as funções e atividades de governo no Plano, caracterizando-o por uma junção de propostas e metas desconexas entre si e baixo grau de intersetorialidade, e iv) participação da sociedade existente, embora fragmentada e embrionária.

As avaliações de membros do Executivo e do Legislativo diante destas experiências de participação cidadã são positivas, embora haja problemas de sincronicidade com os instrumentos de planejamento existentes:

E sobre esse aspecto, ele [o Plano de Metas] hoje merece uma reflexão também desses agentes externos, porque ele está totalmente descasado com [sic] as outras ferramentas de planejamento da prefeitura. [...] os prazos que você tem que entregar o Plano de Metas, PPA, tudo isso: não casa. Logo, eles não têm sincronicidade. Se não tem sincronicidade, a gestão disso fica muito mais confusa, a auditoria fica muito mais difícil e a transparência também fica muito nebulosa sobre esse aspecto. Temos que avançar muito (Representante da Secretaria de Planejamento Municipal 2).

Outro instrumento relevante, o Plano Diretor, foi discutido na cidade por vários anos. O processo envolveu idas e vindas no desenho institucional para elaboração e participação cidadã, com centralização no Executivo, debate no Legislativo e intervenção do Ministério Público e Judiciário (Florianópolis, 2015).

No mandato 2013-2016, a Prefeitura iniciou o programa Orçamento no Bairro, o qual não alcançou resultados significativos, inclusive por falta de recursos para implementação. Foi retomado por iniciativa de alguns vereadores na gestão 2017-2020. Alguns investimentos na cidade foram realizados por adesão ao PAC, do governo federal. Mais recentemente, o município vem se engajando na elaboração de planos com outros municípios da região metropolitana, como os de Saneamento e de Mobilidade (Plamus, 2018). Esses planos foram uma exigência definida pelos ministérios e secretarias dessas áreas, aliada a uma estratégia do governo do estado de priorizar atendimento a demandas de regiões metropolitanas.

Em síntese, os principais achados da pesquisa no município são:

- Transição do planejamento para o desenvolvimento ao planejamento gerencial e societal, no período entre 1965 e 2017, com primazia do planejamento de longo prazo até 1980 e primazia gerencial com elementos societais após 1980;

- Prioridades municipais influenciadas por diretrizes e programas nacionais, combinadas com o desenvolvimento de capacidade técnica e política que o levam a alcançar indicadores socioeconômicos acima das médias nacionais;

- Dificuldade de articulação entre os diferentes mecanismos de planejamento e alocação de recursos (setorial, curto e longo prazo, entes federados, governo-cidadão);

- Após os anos 2000, iniciativas do governo e da sociedade civil local, gerando aprendizagem social sobre planejamento e alocação, porém enfrentando fragmentação e descontinuidades.

Em diálogo com a literatura, o estudo desse município nos permite indicar dois grandes desafios para o planejamento municipal:

i) Superar a dicotomia entre o planejamento para o desenvolvimento, o planejamento gerencial e o engajamento cidadão preconizado pela abordagem societal (Cepal, 2000a; Bresser-Pereira, 2008; Paula, 2005);

ii) O equilíbrio e a coordenação entre os mecanismos de planejamento e gestão intersetoriais e intergovernamentais, e destes com as leis orçamentárias.

Ainda que a coordenação de políticas setoriais venha avançando no país, é ainda dependente da iniciativa do governo central e das barganhas políticas (Souza, 2018; Souza \& Machado, 2018), e há um descasamento entre as expectativas expressas no planejamento e a sua execução (Cardoso Jr., 2014; Abrucio \& Loureiro, 2005; Pagnussat, 2006; Giambiagi \& Além, 2009). 


\section{CONSIDERAÇÕES FINAIS}

Ao analisar as prioridades do planejamento de investimento - PTIs e PPAs - no município de Florianópolis, de 1965 a 2017, identificam-se algumas razóes que explicam essas prioridades e apontam-se elementos para o debate sobre planejamento municipal.

No período de 1950 a 1980, o planejamento em Florianópolis orienta-se para o longo prazo, priorizando funções de governo como infraestrutura e transportes, em sintonia com a lógica desenvolvimentista pautada no modelo de reforma social, que influenciou a orientação da Cepal para a industrialização na América Latina.

No segundo momento, a CF/88 instituiu os PPAs como planos de médio prazo e os planos setoriais, de longo prazo, prevendo definição de objetivos, metas e indicadores de resultados e mecanismos de participação cidadã e controles social e institucional interno e externo. A pesquisa demonstrou uma mudança gradativa de prioridades. Nos anos 2000, os maiores investimentos, em média, ocorreram nas funções de governo saúde e saneamento, administração e educação e cultura. Quanto ao enfoque do planejamento, observa-se a combinação dos modelos de reforma social e aprendizagem social.

Em termos do volume de recursos, o município reflete na sua alocação as definições constitucionais e a estrutura institucional das políticas do governo central. Ainda que se pudesse esperar mais autonomia, dada sua capacidade técnica e política e seus bons indicadores socioeconômicos, a pesquisa demonstrou que predomina a alocação definida centralmente. $\mathrm{O}$ bom desempenho relativo do município pode ser explicado tanto por tais capacidades como pelas tentativas de articulação entre governo e cidadania na definição de prioridades e sua execução, a exemplo do Plano de Metas e da Rede de Monitoramento Cidadão. Em áreas como a da saúde, o conselho municipal e alguns conselhos locais desempenham papel relevante.

As iniciativas de inovação institucional (Plano de Metas, Rede de Monitoramento Cidadão, etc.), ainda que fragmentadas, têm buscado criar alternativas para identificar prioridades e acompanhar metas e indicadores, gerando aprendizagem social em Florianópolis. Todavia, há que avançar na coordenação entre agentes públicos e sociais para que estes possam participar na tomada de decisão de modo mais contínuo, menos fragmentado.

Verifica-se, ainda, fragilidades na articulação entre os mecanismos de planejamento e gestão intersetoriais e intergovernamentais, e destes com as leis orçamentárias. Algo observado no âmbito nacional, embora tenha havido avanços em capacidade de coordenação de políticas nos últimos 30 anos.

No que se refere à relação entre planejamento para o desenvolvimento e os modelos gerencial e societal, a pesquisa reforça a necessidade de conciliar tais enfoques. O planejamento municipal se beneficiaria de uma visão de longo prazo, com compromisso intergeracional no que tange a infraestrutura, saúde e educação, articulado a mecanismos de gestão que visem a qualidade nos serviços públicos e o engajamento cidadão na definição de prioridades, em harmonia com a alocação de recursos nas leis orçamentárias.

Para futuros estudos, faz-se necessário avançar na análise comparativa com outros municípios e na investigação de outras razões que colocam o município estudado em uma boa condição relativa no cenário nacional, apesar dos limites na integração do planejamento e dos riscos decorrentes. Além disso, é preciso investigar em que medida o planejamento considera dados e demandas das diferentes áreas do município.

\section{REFERENCIAS}

Abrucio, F. L.; Loureiro, M. R. (2005) Finanças públicas, democracia e accountability. In: Arvate, P. R.; Biderman, C. Economia do setor público no Brasil. Rio de Janeiro: Elsevier/Campus, (75-102).

Abrucio, F. L. (2008) Trajetória recente da gestão pública brasileira: um balanço crítico e a renovação da agenda de reformas. Revista de Administração Pública. Edição Especial Comemorativa: 67-86, 1967-2007. 
Atlas Brasil (2018) Atlas do desenvolvimento humano no Brasil. Ranking todo o Brasil 2010. Recuperado de http:// www.atlasbrasil.org.br/2013/pt/ranking. Acesso: 02 set 2018.

Avritzer, L. (2012) Sociedade civil e Estado no Brasil: da autonomia à interdependência política. Opinião Pública, Campinas, 18 (2): 383-398.

Brasil. (2015) Constituição da República Federativa do Brasil (1988). Brasília. Recuperado de http:// www.planalto.gov.br/ccivil_03/constituicao/constituicaocompilado.htm. Acesso: 08 maio 2018.

Brasil. (2017) Ministério do Planejamento: PAC. Recuperado de http://www.pac.gov.br/sobre-o-pac. Acesso: 19 mar 2018.

Bresser-Pereira, L. C. (2008) O modelo estrutural de gerência pública. Revista da Administração Pública (RAP), 47(2): 391-410.

Bresser-Pereira, L. C. (1998) Da administração pública burocrática à gerencial. In: Bresser-Pereira, L. C.; Spink, P. Reforma do estado e administração pública gerencial. Rio de Janeiro: Editora Fundação Getúlio Vargas. (237-270).

Cáceres, P. (2014) Planes y programas de metas como innovaciones en los procesos de rendición de cuentas en el nivel local: Experiencias en el marco de la Red Latinoamericana por Ciudades y Territorios Justos, Democráticos y Sustentables. In: Pinheiro, D.; Melo, D., Costa, J. In: Democracia: desafios, oportunidades e tendências. Florianópolis: Imaginar o Brasil. (292-344).

Casarotto Filho, N.; Pires, L. H. (2001) Redes de pequenas e médias empresas e desenvolvimento local: estratégias para a conquista da competitividade global com base na experiência italiana. São Paulo: Atlas.

Cardoso, F. H. (1993) Livros que inventaram o Brasil. São Paulo, Novos Estudos, 37: 21-35.

Cardoso Jr, J. C. (2014) Planejamento governamental e gestão pública no Brasil: balanço da experiência federal e desafios no séc. XXI. In: Cardoso Jr, J. C.; Coutinho, R. Planejamento estratégico em contexto democrático: lições da América Latina. Brasília: ENAP.

Cepal. (2000a) Introdução à técnica de planejamento. In: Bielschowsky, R. (org). Cinquenta anos de pensamento da CEPAL. Rio de Janeiro: Record.

Cepal. (2000b) Estudo econômico da América Latina. In: Bielschowsky, R. Cinquenta anos de pensamento da CEPAL. Rio de Janeiro: Record.

Costa, F. L. da. (2008) Brasil: 200 anos de Estado; 200 anos de administração pública; 200 anos de reformas. Revista de Administração Pública, 42 (5): 829-874.

Dagnino, E. (2002). Sociedade civil, espaços públicos e a construção democrática no Brasil: limites e possibilidades. Dagnino, E. (org). Sociedade civil e espaços públicos no Brasil. São Paulo: Paz e Terra.

Dahmer, J. (2014) Ação coletiva, governança democrática e accountability social na construção de cidades sustentáveis: os casos de Florianópolis, Ilhabela e Ilhéus (Dissertação de Mestrado). Florianópolis, Universidade do Estado de Santa Catarina, Florianópolis.

Florianópolis. (2015) Lei Complementar no 482, de 17 de janeiro de 2014 (2014). Institui o Plano Diretor de urbanismo do município de Florianópolis que dispõe sobre a política de desenvolvimento urbano, o plano de uso e ocupação, os instrumentos urbanísticos e o sistema de gestão. Recuperado de https:// www.leismunicipais.com.br/a1/plano-diretor-florianopolis-sc. Acesso: 13 jan 2018

FloripAmanhã. (2018) Rede de Monitoramento Cidadão. Recuperado de http://floripamanha.org/2018/05/rede-demonitoramento-cidadao-prefeitura-ja-tem-40-dos-indicadores-que-serao-apresentados-neste-ano/. Acesso: 03 jun. 2018.

Fortes, A. (2007) O Estado Novo e os trabalhadores: a construção de um corporativismo latino-americano. Locus: revista de história, Juiz de Fora, 13 (2): 61-86.

Frank, B.; Vibrans, A. C. (2003) uma visão integrada da bacia hidrográfica. In: Frank, B.; Pinheiro, A. Enchentes na Bacia do Rio Itajaí: 20 anos de experiências. Blumenau: FURB (191-222).

Garcia, R. C. (2015) A reorganização do processo de planejamento do governo federal: o PPA 2000-2031. In: Cardoso Jr, J. C.; Cunha, A. S. (org) Planejamento e avaliação de políticas públicas. Brasília: Ipea. 
Giacomoni, J. (2012) Orçamento público. São Paulo: Atlas.

Giambiagi, F.; Além, A. C. (2008) Finanças públicas: teoria e prática no Brasil. 3 ed. Rio de Janeiro: Elsevier.

Goularti Filho, A. (2002) Formação econômica de Santa Catarina. Florianópolis: Cidade Futura.

IBGE - Instituto Brasileiro de Geografia e Estatística. (2018) IBGE Cidades. Florianópolis. Recuperado de https://www.ibge.gov.br/estatisticas-novoportal/por-cidade-estadoestatisticas.html? $\mathrm{t}=$ destaques\&c=4205407. Acesso: 31 ago 2018 .

Lastres, H. M. M. ; Cassiolato, J. E. (2003) Sistemas de inovação e arranjos produtivos locais: novas estratégias para promover a geração, aquisição e difusão de conhecimento. Revista Centro de Ciências Administrativas: Fortaleza: [s.n.]. 9 (2): 189-195.

Lemos, C. (2003) Micro, pequenas e médias empresas no Brasil: novos requerimentos de políticas para a promoção de sistemas produtivos locais. (Tese de Doutorado). Programa de Pós Graduação em Engenharia de Produção. Rio de Janeiro: UFRJ.

Menezes, C. O. M. (2009) Industrialização e meio ambiente no estado de Santa Catarina: estudo de caso sobre a evolução e os impactos socioambientais do segmento têxtil-vestuarista na microrregião do Alto Vale do Itajaí. Tese (Doutorado em Sociologia Política). Programa de Pós-graduação em Sociologia Política. Florianópolis: UFSC.

Menezes, E.C.O.; Schommer, P.C.; Rocha, A.C.; Turnes, V.A.; Alves, M.R. (2015) Planning, Accountability and Local Governance: the implementation of the Plan of Goals in a Brazilian City. IRSPM Conference 2015, Birmingham, 30 March-1 April.

Organização das Nações Unidas no Brasil - ONUBR. (2018) Agenda 2030 para o desenvolvimento sustentável. Recuperado de https://nacoesunidas.org/pos2015/agenda2030/. Acesso: 30 ago 2018.

Pagnussat, J. L. (2006) Introdução. In: Giacomoni, J.; Pagnussat, J. L. (org). Planejamento e Orçamento governamental. Brasília: ENAP.

Paula, A. P. (2005) Administração pública brasileira entre o gerencialismo e a gestão social. RAE Debate, 45 (1), jan/ mar.

Plamus, Plano de Mobilidade Urbana Sustentável da Grande Florianópolis. (2018) Recuperado de http:// www.plamus.com.br/index.php. Acesso: 14 Set 2018.

REE-F. (2018) Ranking de Eficiência dos Estados - Folha. Recuperado de https://temas.folha.uol.com.br/reef/reportagens-e-analises/ranking-estadual-leva-em-conta-17-variaveisagrupadas-em-6-componentes.shtml. Acesso: 30 ago 2018.

REM-F. (2018) Ranking de Eficiência dos Municípios - Folha 2016. Recuperado de https://www1.folha.uol.com.br/ remf/. Acesso: 30 ago 2018.

Richardson, R. J. et. Al (1985) Pesquisa social: métodos e técnicas. São Paulo: Atlas.

Rocha, A. C. (2013) A realização da accountability em pareceres prévios do Tribunal de Contas de Santa Catarina. Rev. Adm. Pública, 47 (4): 901-926.

Sachs, I. (1993) Estratégias de transição para o século XXI: desenvolvimento e meio ambiente. São Paulo: Studio Nobel e Fundap.

Sachs, I. (2007) Rumo à ecossocioeconomia: teoria e prática do desenvolvimento. São Paulo: Cortez.

Sinais Vitais Florianópolis. (2018) Recuperado de http://www.icomfloripa.org.br/wp-content/uploads/2017/05/ Sinais-Vitais-2016-Florian\%C3\%B3polis-Crian\%C3\%A7a-e-Adolescente-05.17.pdf. Acesso: 08 ago.

Souza, C. (2018) Coordenação de políticas públicas. Brasília: Enap.

Souza, M. M.; Machado, J. A. (2018) Federalismo e políticas públicas. Brasília: Enap.

Triviños, A. (1987) Introdução à pesquisa em ciências sociais. São Paulo: Atlas.

Vieira, P. F. (2006) Rumo ao desenvolvimento territorial sustentável: esboço de roteiro metodológico participativo. Eisforia: desenvolvimento territorial sustentável: conceitos, experiências e desafios teórico-metodológicos. Florianópolis, 4 (especial), dez. 
Elaine Cristina de Oliveira Menezes, et al. Planejamento Municipal em Debate: Trajetória e Priorid...

Vieira, P. F.; Weber, J. (2000) Introdução geral: sociedades, natureza e desenvolvimento viável. In: Vieira, P. F.; Weber, J. Gestão de recursos naturais renováveis e desenvolvimento: novos desafios para a pesquisa ambiental. São Paulo: Cortez.

\section{Notas}

[i] O sistema corporativo é considerado uma das marcas do Estado Novo (1937-1945), estabelecendo mecanismos de reconhecimento dos direitos e das formas de representação dos trabalhadores, de maneira autoritária. A experiência brasileira de pacto corporativista expressava uma tendência mundial verificada, também, em outros países da América Latina nas décadas 1930 e 1940 (Fortes, 2007; Costa, 2008).

\section{BY-NC-ND}

